\title{
分析化学实验渐进融入课程思政的混合式教学初探
}

\author{
刘晓庚 ${ }^{*}$, 刘琴, 李彭, 邰佳, 彭冬梅 \\ 南京财经大学食品科学与工程学院, 应用化学系, 南京 210023
}

\begin{abstract}
摘要: 课程思政已在广大教师中深入人心, 形成了共识。不同课程如何围绕着 “立德树人” 挖掘本课程的思政元素, 构建起全员、全程、全课程、全方位育人教育, 使课程教学与思政育人同向同行, 形成协同效应, 这是课程思政之 根本。为此我们以分析化学实验课程为例, 探讨了渐进融入式的课程思政的混合式教学, 从教学过程的总体设计、 教学目标设计和渐进融合课程思政元素的教学模块设计三个方面进行了尝试实践, 获得了良好效果。
\end{abstract}

关键词: 分析化学实验; 教学改革; 课程思政; 教学设计

中图分类号: G64; O6

\section{A Preliminary Study on the Mixed Teaching of Analytical Chemistry Experiment Gradually Integrated into the Course of Ideological and Political Education}

\author{
Xiaogeng Liu *, Qin Liu, Peng Li, Jia Tai, Dongmei Peng \\ Department of Applied Chemistry, School of Food Science and Engineering, Nanjing University of Finance and Economics, \\ Nanjing 210023, China.
}

\begin{abstract}
Course ideology and politics education has been deeply rooted in the hearts of the majority of teachers, forming a consensus. How to excavate the ideological and political elements around the "moral cultivation" of different courses, and build a full staff, full course, all-round education, so that the curriculum and ideological and political education go together in the same direction to have synergistic influence, is the key problem to be solved. Taking the course of analytical chemistry experiment as an example, this paper discusses the gradual integration of course ideology and politics mixed teaching, from the perspectives of the overall design of the teaching process, the design of teaching objectives and the teaching module design of gradual integration of ideological and political elements of the course. Satisfying results have been achieved.
\end{abstract}

Key Words: Analytical chemistry experiment; Teaching reform; Course ideology and politics; Teaching design

课程思政是以构建全员、全程、全课程、全方位育人格局的形式将各类课程与思想政治理论课 同向同行, 形成协同效应, 把 “立德树人” 作为教育的根本任务的一种综合教育理念 ${ }^{[1]}$ 。即施教者在 各类专业课教学中有计划、有目的地将思想政治教育的元素融入教学过程中, 使受教者在学习科学 知识、习得技术技能的同时, 受到思想政治教育, 引领学生坚定理想信念, 弘扬社会主义核心价值 观, 培养良好的道德品质的新教学理念 ${ }^{[2]}$ 。分析化学实验作为高校食品类专业的重要专业基础课,

收稿: 2020-10-08; 录用: 2020-12-14; 网络发表: 2020-12-18

“通讯作者, Email: 9120021010@nufe.edu.cn

基金资助: 南京财经大学教学成果培育项目(JXCG1910) 
其融入丰富的思想政治教育元素是其当今教学改革的必然。但如何融入思政的整体方案设计、教学 目标设置、教学内容和教学方法等的设计, 均是实施和实现分析化学实验课程思政的核心和关键。 从2018年开始我校的分析化学实验就在课程思政上进行了初探, 本文总结了我们的尝试, 希望得到 大家的赐教与指正。

\section{1 渐进式融合课程思政的教学过程总体设计}

本着 “立德树人”确保教学工作积极、稳妥、顺利和课程思政到位的指导思想, 我们将新事物 的课程思政采用渐进式融入分析化学实验课程。分析化学实验渐进式课程思政教学过程的总体设计 如图1所示。

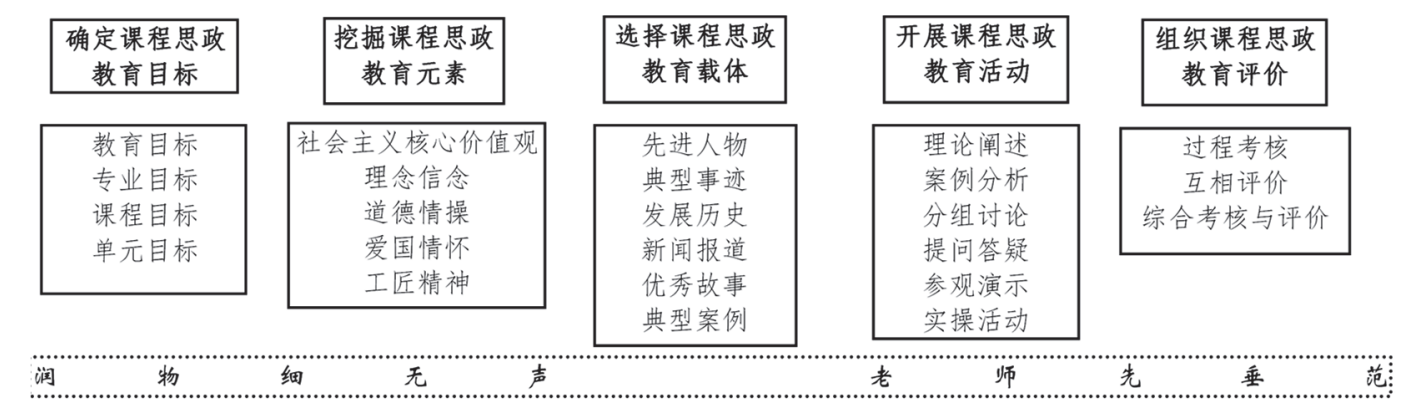

图1＼cjkstart分析化学实验渐进式课程思政教学过程总体设计示意图

从课程思政教育目标和挖掘课程思政教育元素开始, 到思政教育载体、教育活动、教学组织和 评价等全教学过程, 进行全方位形成分析化学实验的课程思政总体过程的设计。以突显出渐进、稳 妥和分析化学实验本身特征的特色。

\section{2 渐进式融合课程思政的教学目标设计}

基于分析化学实验已建立的线上(南京财经大学网络教学平台 http://mooc1.chaoxing.com/ mycourse/teachercourse?)和线下(带多媒体的分析化学实验室)的教学平台, 为体现国家意志将分析化 学实验的渐进式融入课程思政的混合式教学目标设计如图2所示。

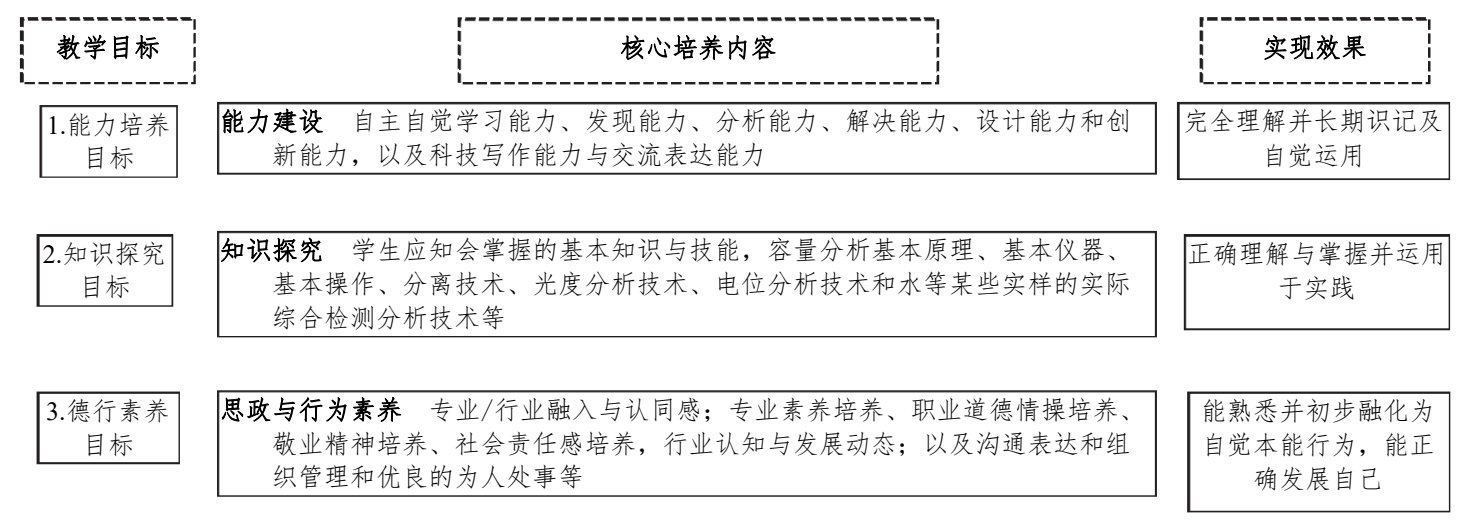

图2 渐进式课程思政下分析化学实验课程目标的设置

根据此教学目标的设计对分析化学实验讲义和教案进行了重新疏理和编撰, 做到着实让教材讲 义和教案成为分析化学实验课程思政的重要载体, 充分发挥讲义教材铸魂育人、关键支撑、固本培 元、文化交流等功能和作用 ${ }^{[3]}$ 。因此, 传授科学知识、技术技能的同时, 又对学生强化思想政治教 
育, 弘扬社会主义核心价值观, 培育学生的科学世界观和工匠精神, 进一步夯实分析化学实验课程 的思政育人基础。在编撰中既要遵循分析化学实验课程标准, 又要敢于创新实验内容, 注重突破, 努力挖掘课程中的思政教育元素, 并与课程内容及发展历史等紧密结合, 讲授时还可进一步与自身 理解、体会和社会需求等融通, 实现卓越的课程思政育人成效。

\section{3 渐进融合课程思政元素的教学模块设计}

有了分析化学实验渐进式课程思政教学过程的总体设计和课程目标设置后, 关键就是落实到每 个具体实验项目的教学模块。因此, 根据我校分析化学实验课程的基础与特色 ${ }^{[4,5]}$, 结合当前形势需 求, 设计了基于线上线下混合式教学的分析化学实验渐进式融合课程思政元素的教学模式, 及典型 教学内容的融入教学模块(见表1)。下面以食醋的测定实验为例, 先让学生线上汶览(约25分钟)中国 四大名醋之镇江香醋、恒顺集团的简介视频, 醋的应用短片和醋品品鉴大师林田中成长历程的图文 简介, 分别领略悠久而灿烂的中华优秀食醋文化和忘我工作、刻苦钻研的工匠精神和热忱帮带、 团结协作团队作风。在激发学生对食醋的兴趣后引入课程主题食醋品质的保障手段一一食醋含量的 测定, 学生进行了线上食醋测定全程操作录像和虚拟仿真的学习(约40分钟)。学生对照分析化学理 论课所学知识, 能加深理解食醋测定的原理、方法及操作, 并完成预习报告(线上提交), 然后进入实 验室。先进行食醋的取样与处理、滴定分析指示剂的选择, 以及测定误差的来源等问题的讨论和教 师总结(约 40 分钟), 接下来学生能较轻松而较熟练地顺利完成好实验的实操训练(约 120 分钟)。学生 提交测定数据并整理好实验室后, 于当周提交带有实验结果分析和改进实验建议等内容的实验报告, 教师通过学习群一对一地及时批阅和反馈实验及报告等相关问题。这样学生既能理解 “理论-实践理论”的现代学习模式, 又能深深体会到温暖的师生情感和融洽的分析化学实验教学氛围。

\section{表1 分析化学实验渐进融合课程思政元素的混合式教学模块的典型设计}

\begin{tabular}{|c|c|c|c|c|}
\hline 序号 & 授课要点 & 可挖掘的思政映射与融合点 & 混合教学模式 & 预期可达到的效果 \\
\hline \multirow[t]{11}{*}{1} & 绪论和称量练 & 1) 国内外分析检测科学与技术发展现 & 线上平台: & 1) 我国是工业制造和产销的第一大国, 产品质量随 \\
\hline & 习与滴定练习 & 状; & 学术报告 & 检测技术发展而紧跟国际先进水平; \\
\hline & & 2) 我国分析化学实验发展历史与未 & 新闻媒介 & 2) 了解我国分析检测产业的发展历史及现状, 与学 \\
\hline & & 来; & 线下课堂: & 生产生共鸣; \\
\hline & & 3) 江苏省食品与化学产业现状与存在 & 课堂讨论 & 3) 树立自信感、认同感、幸福感和自豪感; \\
\hline & & 问题; & 翻转课堂 & 4) 学好基础, 坚固专业思想, 服务民族伟大复兴战 \\
\hline & & 4) 分析检测科技发展与产品质量提升 & 实操训练 & 略; \\
\hline & & 和国民经济发展的关系; & & 5) 增强学生对未来职业发展的信心与决心; \\
\hline & & 5) 我国分析检测等基础科技的现状与 & & 6) 实现德育, 塑造品格, 厚植爱国主义精神; \\
\hline & & 未来发展趋势; & & 7) 激发学生为国为民的学习热情和动力; \\
\hline & & 6) 容量分析的前世今生及未来前景。 & & 8) 树立服务地方经济、践行使命担当的决心和毅力。 \\
\hline \multirow[t]{7}{*}{2} & $\mathrm{NaOH}$ 标准溶 & 1) “酸碱” 是传统的化工业基础, 也是 & 线上平台: & 1) 挖掘传统食品文化, 传递真善美; \\
\hline & 液的配制标定 & 我国民族工业的启蒙; & 视频资源 & 2) 学会基于 “理论-实践-理论” 模式, 深刻认识事 \\
\hline & 与食醋的测定 & 2) 从镇江的三宝, 到食醋酸度测定; & 人物介绍 & 物发展的基本规律; \\
\hline & & 3) 粮食储藏与安全及酸碱密切相关。 & 线下课堂: & 3）感受中华民族的智慧和力量; \\
\hline & & & 课堂讨论 & 4) 能够透过现象看本质, 提出解决问题的策略。 \\
\hline & & & 翻转课堂 & \\
\hline & & & 实操训练 & \\
\hline
\end{tabular}


(续表1)

\begin{tabular}{|c|c|c|c|c|}
\hline 序号 & 授课要点 & 可挖掘的思政映射与融合点 & 混合教学模式 & 预期可达到的效果 \\
\hline \multirow[t]{9}{*}{3} & $\mathrm{HCl}$ 标液的配 & 1）食碱的应用及国标测定方法; & 线上平台: & 1) 近代化工奠基人候德榜及爱国主义教育; \\
\hline & 制标定与食碱 & 2) 候德榜制碱法与爱国主义精神; & 视频资源 & 2) 发扬艰苦奋斗, 自力更生, 力争卓越的精神; \\
\hline & 的测定 & 3）食碱制备新技术进展与趋势。 & 人物介绍 & 3) 要谦虚谨慎, 要求真务实; \\
\hline & & & 线下课堂: & 4) 科学问题的解决最终目的是要落地, 成果要实现 \\
\hline & & & 课堂讨论 & 实际转化; \\
\hline & & & 实操训练 & 5) 科技的发展是为了推动人类生活的进步。 \\
\hline & & & 课堂拓展: & \\
\hline & & & 案例分析 & \\
\hline & & & 企业考察调研 & \\
\hline \multirow[t]{9}{*}{4} & EDTA标液的 & 1) EDTA滴定法与诺贝尔奖; & 线上平台: & 1) 科学无国界, 科技是属于全人类; \\
\hline & 标定与水硬度 & 2) 我国水质污染现状; & 视频资源 & 2) 民以食为天, 食以安为先; \\
\hline & 的测定 & 3) 水硬度的测定方法; & 人物介绍 & 3) 科学是把双刃剑, 要发挥科技向善的力量; \\
\hline & & 4) 微型滴定分析技术; & 线下课堂: & 4) 继承发扬中华民族的勤俭节约优良传统; \\
\hline & & 5) 绿色分析测试技术; & 课堂讨论 & 5) 树立绿色环保持续发展的科学理念; \\
\hline & & 6) 水质测定的中国贡献。 & 实操训练 & 6) 基于课程理论知识, 能够理解相关测定标准方法, \\
\hline & & & 课堂拓展: & 学会解决常规品质的测定问题。 \\
\hline & & & 案例分析 & \\
\hline & & & 水质调研与检测 & \\
\hline \multirow[t]{9}{*}{5} & $\mathrm{KMnO}_{4}$ 的配制 & 1) 自身指示剂与氧化还原滴定法; & 线上平台: & 1) 熟悉某一成分的测定方法远不止一种, 要学会选 \\
\hline & 标定与 $\mathrm{H}_{2} \mathrm{O}_{2} 、$ & 2) $\mathrm{KMnO}_{4} 、 \mathrm{H}_{2} \mathrm{O}_{2}$ 的特性和应用; & 视频资源 & 择和优化; \\
\hline & 水中COD的测 & 3) 水质 COD (化学需氧量)标准及测定 & 新闻媒介 & 2) 了解我国水质标准的发展历史; \\
\hline & 定 & 方法。 & 线下课堂: & 3）树立 “绿水青山就是金山银山” 的和谐绿色可持 \\
\hline & & & 对分课堂 & 续发展观, 开发新型绿色准确快速测定技术, 实现检 \\
\hline & & & 实操训练 & 测技术的提档升级; \\
\hline & & & 课堂拓展: & 4) 深刻理解科学研究的根本目的就是更好的服务人 \\
\hline & & & 标准解读 & 类和建立人与自然更加和谐发展的正确关系。 \\
\hline & & & 水质调研 & \\
\hline \multirow[t]{9}{*}{6} & 邻二氮菲分光 & 1) 铁是生命元素, 微量铁测定方法; & 线上平台: & 1) 善于发现, 敢于求新求变的创新精神; \\
\hline & 光度法测定铁 & 2) 仪器分析法的适用准则; & 视频资源 & 2) 树立正确的专业观和职业道德情操; \\
\hline & & 3) 微量及超微量成分检测方法的开发 & 新闻事件 & 3) 培养学生高尚的品德和扎实过硬的基础; \\
\hline & & 与新型技术的发现和应用。 & 线下课堂: & 4) 树立爱岗敬业、精益求精、专注创新的工匠精神; \\
\hline & & & 课堂讨论 & 5) 培养学生终生学习优良习惯和持续发展的核心理 \\
\hline & & & 实操训练 & 念。 \\
\hline & & & 课堂拓展： & \\
\hline & & & 案例分析 & \\
\hline & & & 高铁食物调研 & \\
\hline
\end{tabular}

按表1所设计的内容再通过 “周周金点子” 和 “一实验一金话题” 等课堂拓展项目活动, 进一步 加强分析化学实验教学与思政教育的无缝对接和深度融合, 激发他们的学习兴趣及参与度, 同时注 重线上线下结合, 增强师生之间的交流互动; 还要重视因材施教以及采用情境和演示等多种方式教 学, 适时适当融入思政教育, 使实验课堂既活跃又融洽, 提高学生的实验热情、带入感、专业认同 
感和社会责任感, 树立对专业和中华文化的自信, 养成良好的人格, 真正实现思政教育在专业基础 课教学中 “润物细无声” 和显隐结合, 避免了专业课程教学中生搬硬套或东拼西凑式的思政教育 ${ }^{[6]}$ 。

另外, 要注重发挥学生的主体作用和主观能动作用, 营造主动学习的氛围, 使活学活用的翻转 课堂模式成为常态甚至主流 ${ }^{[7]}$, 还需要制定配套的科学考评办法, 使师生在分析化学实验的授课与 学习活动中有事半功倍之效和满满的获得感 ${ }^{[8]}$ 。

\section{4 结语}

以社会主义核心价值观为指导, 经过 3 轮 24 个实验班(每班不超过 20 人, 安排 2 名指导教师)分析 化学实验课程思政的初步探索和教学实践。我们的体会是：首先教师要有乐意接受课程思政的意识 和课程观, 才能挖掘出分析化学实验课程内容所隐含的师生喜欢的思政元素, 真正形成 “价值引领、 能力培养、知识传授” 的育人导向 ${ }^{[9]}$, 这点是至关重要的前提; 其次要遵循教育教学规律, 将显性专 业知识传授与隐性思政教育有机融合, 才能避免 “两张皮” 现象, 使得教学内容更加丰富、气氛更 加生动活跃。实践结果显示学生完成实验的质量高了、速度也快了, 学习积极高, 师生互动频率增 多且互动质量提高, 课程成绩的优秀率明显增加; 学生专业思想更加稳固, 转专业情况有所好转且 更理性, 参加各种活动的积极性和取得各种奖项的数量和质量均有提升; 教师对课程思政的认识更 加深刻、兴趣也越来越浓烈, 授业、解惑中润物细无声地自觉融入思政层面的 “传道” 热潮正在形 成, 发挥课程育人的主阵地作用, 实现专业课程教学与思政课程同向同行, 形成协同效应, 实现让 每位学生更加热爱分析化学实验等课程, 更加笃定自己的专业选择, 为培养既红又专的社会主义 “四 有”人才而努力践行好课程思政这个新时代的使命。

\section{参 考 文 献}

[1] 田鸿芬, 付洪. 未来与发展, 2018, 42 (4), 99.

[2] 宋伟. 中共济南市委党校学报, 2018, No. 5, 104.

[3] [2020-09-24]. https://www.sohu.com/a/420623663_284449

[4] 刘晓庚. 广州化工, 2016, 44 (20), 184.

[5] 刘晓庚, 苏畅, 周佳虹, 王芳敏, 邓梦浩, 邰佳, 李心悦, 彭冬梅. 农产品加工, 2019, No. 10, 115.

[6] 刘振天. 中国高等教育, 2017, No. 17, 49 .

[7] 苏海红, 林僖. 上海管理科学, 2020, 42 (5), 122.

[8] 高燕. 中国高等教育, 2017, No. Z3, 11 .

[9] 焚兴丽. 人民论坛, 2019, No. 25, 102. 